\title{
PHARMACOECONOMIC EVALUATION OF ACUTE EXACERBATIONS OF CHRONIC OBSTRUCTIVE PULMONARY DISEASE AT A TERTIARY CARE TEACHING HOSPITAL IN NORTH KARNATAKA, INDIA
}

\author{
RAHUL $S^{1}$, ABHINAND CR ${ }^{1}$, NIKITHAREDDY $B^{1}$, JAYACHANDRA ${ }^{1}$, LAKSHMI ${ }^{1}{ }^{1}$, DODDAYYA H ${ }^{1}$, ANTIN SS ${ }^{2}$ \\ ${ }^{1}$ Department of Pharmacy Practice, N. E. T. Pharmacy College, Raichur - 584 103, Karnataka, India. ${ }^{2}$ Department of General Medicine,
} Navodaya Medical College Hospital and Research Centre, Raichur, Karnataka, India. Email: abhinandcr07@gmail.com

Received: 18 January 2018, Revised and Accepted: 13 April 2018

ABSTRACT

Objective: The objective of the study was to evaluate the burden of cost in patients of acute exacerbations of chronic obstructive lung disease (COPD).

Methods: A prospective, observational study was conducted in COPD patients over a period of 6 months in general medicine and pulmonary wards of Navodaya Medical College Hospital and Research Centre, Raichur, Karnataka, India. Direct medical and non-medical cost were included in the burden of cost. From the drug rate manual of hospital, cost for drugs and investigation were calculated.

Results: Overall 100 COPD patients were enrolled in which 92 were male and 8 were female with a mean age of $60.33 \pm 10.98$. The patients participated in this study were stayed in the hospital with mean \pm standard deviation (SD) value of $9 \pm 3$. Minimum total direct medical cost was Rs. 1149.00 and maximum was Rs. $13,510.00$ with a mean \pm SD 3297.48 \pm 1634.226 , in which medicine cost was high (mean 2746.63). Minimum total direct nonmedical cost was Rs. 100.00 and maximum was Rs. 3470.00 with a mean \pm SD $700.7 \pm 487.121$, in which food expenses was high (mean 549.55). Maximum total direct cost was Rs.16,980.00 and minimum was 1349.00 with a mean \pm SD 3998.18 \pm 1921.47 . Direct medical cost contributes $79.56 \%$ and direct non-medical cost contribute $20.44 \%$ of total direct cost.

Conclusion: COPD has a substantial impact on health-care costs particularly for hospitalization. Exacerbation prevention resulting in reduced need for inpatient care could lower costs. The development of pharmacoeconomic is at an infancy stage in India at the moment, despite the rapid growth of clinical research. In a country with scarce resources and an ever-growing population with diverse health-care needs, health economics (Pharmacoeconomic evaluation) plays a pivotal role in determining the delivery of equitable and cost-effective health services.

Keywords: Chronic obstructive pulmonary disease, Total direct cost, Pharmacoeconomic.

(c) 2018 The Authors. Published by Innovare Academic Sciences Pvt Ltd. This is an open access article under the CC BY license (http://creativecommons. org/licenses/by/4. 0/) DOI: http://dx.doi.org/10.22159/ajpcr.2018.v11i5.24814

\section{INTRODUCTION}

Chronic obstructive lung disease (COPD) is a leading cause of morbidity and mortality worldwide that includes an economic and social burden that is both substantial and increasing [1].

COPD prevalence, morbidity, and mortality vary across countries and across different groups within countries. Based on Burden of Obstructive Lung Diseases program (BOLD) and other large-scale epidemiological studies, it is estimated that the number of COPD cases was 384 million in 2010, with a global prevalence of $11.7 \%$ [2].

According to the WHO estimates, 65 million people have moderate to severe COPD. More than 3 million people died of COPD in 2005, which corresponds to $5 \%$ of all deaths globally. Total deaths from COPD are expected to increase by $30 \%$ in the forthcoming 10 years, and there is a need to fasten the studies related to it. It is estimated that by 2030 it is going to take $3^{\text {rd }}$ place in world leading cause of death [3]. The most important risk factor associated with the COPD is cigarette smoking [4].

In India, the total deaths due to COPD in the year 1990 are accounted to be $2.8 \%$ and may increase to $6.5 \%$ by 2020 [5].

Pharmacoeconomics involves the utilization of two major methodologies for health economics analysis: Cost analysis and cost outcomes. Cost analysis considers the costs of providing health-care products or services but does not consider the outcomes experienced by patients or providers. In India, because of growing pressure on the health-care budget, appropriate justification of current expenditures and future investments in public health care are becoming a priority. Pharmacoeconomic analyses are the one which helps in justifying and minimizing this expenditure [6].

Most of the clinicians have little knowledge regarding the health economics as it is a new stream of health care. Clinicians want their patients to receive the best care and outcomes available, and payers want to manage rising costs. As much as $77 \%$ of the healthcare spending in India is in the private sector, of which about $86 \%$ borne out-of-pocket/money. The penetration of insurance schemes in India is very low, estimated at about $10 \%$ of the entire population. This signifies the importance of economic considerations in health care [6].

The economic costs of disease comprises direct costs which include the cost spent for medical care; indirect costs which include costs of lost productivity due to illness, loss of earning due to morbidity, or premature mortality. COPD, in terms of productivity lost, may represent a serious threat to the economy of a developing country like India and data on the pharmacoeconomics of COPD in Indian population is scarce [7]. Hence, a study was conducted to estimate the direct and indirect health-care costs of COPD.

\section{METHODS}

The study was carried out for a period of 6 months from November 2016 to April 2017 after the approval from Institutional Ethics Committee of Navodaya Medical College Hospital and Research Center, Raichur. 
Research design

Type of the study

This was a prospective observational study.

Sample size

A total of 100 samples were selected.

\section{Data collection}

Data were collected from general medicine and pulmonary medicine department using structured data entry format.

\section{Inclusion criteria}

The following criteria were included in this study:

- $\quad$ Age: $18-80$ years

- Sex: Male and Female

- General medicine and pulmonary medicine department inpatients diagnosed with COPD.

\section{Exclusion criteria}

The following criteria were excluded from the study:

- Pregnant/lactating women and children.

- Patients with post-tuberculosis and other lung disorders such as cystic fibrosis and eosinophilic lung disease.

- Patients with ischemic heart disease and evidence of pneumonia.

The study protocol was designated, and the necessity of the study was explained to the HOD of the general medicine department and pulmonary medicine department. An extensive literature survey was carried out regarding the pharmacoeconomic evaluation of acute exacerbation of COPD at a tertiary care teaching hospital in Karnataka.

All the COPD patients admitted to general medicine ward and pulmonary medicine ward were included in the study. The outpatients and other department patients were excluded in the study.

A well-designed patient data collection form was developed and used for this study after obtaining their consent directly from patient/ caretaker. The data collection form was developed by consulting physicians and staffs of pharmacy practice department. The following information such as patient demographic details (name, age, reason for hospitalization, occupation, salary, duration of suffering, smoking history, etc.), direct medical costs (drug used, laboratory tests, and hospital charges), and direct non-medical costs (travel expense, food, and other expenses) was collected from data collection form. The total direct cost covers direct medical and direct non-medical cost using patient case note/prescription all medicine costs were noted and day to day follow-up while attending the ward rounds. The direct medical cost covers the direct medicine cost, laboratory cost, and hospital charges, these were obtained from patient direct inquiry and hospital pharmacy slips, lab reports and lab bills, and hospital charges. The cost of each medicine was taken from latest editions of tertiary sources, inquiries from hospital pharmacy/community pharmacy and also from medicine strips. From these, unit cost of each medicine was calculated. The patients admitted to general wards are not charged for bed, nursing and daily routine examination by doctors. However, the patients they admitted in ICCU, ICU, and special wards are charged for bed, nursing, and daily routine examinations. The direct non-medical costs cover sum of expenses such as travel expenses, food, and other expenses (supporter expenses) which is directly related to the patients. All information relevant to the study was collected at the time of admission to till the day of discharge. The cost of discharge medication had not been included in this study, and the collected data of cost-of-illness were subjected for suitable statistical analysis.

A descriptive statistical analysis has been carried out in the present study. Results on continuous measurements are presented on the mean \pm standard deviation (SD) (Min-Max), and results on categorical measurements are presented in number (\%).

\section{RESULTS}

Patient recruitment for the study was carried out 6 months from November 2016 to April 2017. During this time period, 100 patients with COPD were screened and enrolled into the study based on previously mentioned inclusion and exclusion criteria. Finally, out of 100 patients, 100 patients with COPD are enrolled in this study. The COPD patient's age details were shown in Fig. 1.

Out of 100 patients, $92 \%$ patients were male $(n=92)$, and $8 \%$ were female $(n=8)$ with a mean \pm SD of age $60.33 \pm 10.98$ (Fig. 2 ). The patients participated in this study were stayed in the hospital with mean \pm SD value of $9 \pm 3$ (Fig. 3).

Among 100 patients included majority of the patients, i.e., 37\% were ranging between the age group of 51-60 years and the least, i.e., 8\% were in between 41 and 50 years of age group. Followed by $10 \%, 15 \%$, and $30 \%$ were $31-40$ years, $71-80$ years, and $61-70$ years, respectively.

Out of the 100 patients, $83 \%(n=83)$ patients having complains of cough, 46 patients were having complains of breathlessness, 45 patients were having complains of dyspnea, followed by 37 patients having expectoration and fever (Table 1)

$90 \%(n=90)$ patients were smokers and $10 \%(n=10)$ patients were nonsmokers. 48\% $(\mathrm{n}=48)$ patients admitted with COPD were alcoholics and $52 \%(n=52)$ patients were non-alcoholics (Table 2).

The total direct cost is the sum of the direct medical cost and direct nonmedical cost. Direct medical cost involves the total medicine cost, lab test charges and hospital charges. Direct non-medical cost involves the diet charges and other expenses directly related to the patient.

Direct medical cost minimum, maximum, mean, and SD were Rs. 1149 , $13510,3297.48$, and 1634.22 , respectively, in which medicine cost was found to be more.

Direct non-medical cost minimum, maximum, mean, and SD were Rs. $100,3470,700.7$, and 487.12, respectively, in which food expense was found to be more followed by travel expense.

The mean total direct cost was Rs. 3998.18 with SD of 1921.47 (Table 3).

\section{DISCUSSION}

There were very few studies in India which concentrated on costof-illness in COPD patients. The present study clearly provided the

Table 1: Complains of patients

\begin{tabular}{ll}
\hline Complains of patients & $\mathbf{n}(\mathbf{\%})$ \\
\hline Cough & $83(83)$ \\
Breathlessness & $46(46)$ \\
Dyspnea & $45(45)$ \\
Fever & $37(37)$ \\
Expectoration & $37(37)$ \\
Chest pain & $9(9)$ \\
Loss of appetite & $6(6)$ \\
Common cold & $2(2)$ \\
\hline
\end{tabular}

Table 2: Details on alcohol and smoking status

\begin{tabular}{ll}
\hline Smoking habits & n (\%) \\
\hline Non-smoker & $10(10)$ \\
Smoker & $90(90)$ \\
Total & $100(100)$ \\
Alcohol consumption & \\
Alcoholic & $48(48)$ \\
Non-Alcoholic & $52(52)$ \\
Total & $100(100)$ \\
\hline
\end{tabular}


Table 3: Summary on the distribution of cost analysis of COPD patients

\begin{tabular}{|c|c|c|c|}
\hline Cost analysis & Minimum & Maximum & Mean \pm SD \\
\hline Total medicine cost & 809 & 12530 & $2746.63 \pm 1586.442$ \\
\hline Lab test charges & 250 & 1485 & $543.75 \pm 185.47$ \\
\hline Hospital charges & 0 & 200 & $7.1 \pm 25.556$ \\
\hline Total direct medical cost (Med. Cost+Lab. Cost+Hosp. Cost) & 1149 & 13510 & $3297.48 \pm 1634.226$ \\
\hline Travel & 50 & 320 & $151.15 \pm 61.034$ \\
\hline Food & 0 & 3150 & $549.55 \pm 476.695$ \\
\hline $\begin{array}{l}\text { Total direct non-medical cost (Travel Cost+Food Cost and } \\
\text { Other Expenses) }\end{array}$ & 100 & 3470 & $700.7 \pm 487.121$ \\
\hline Total direct cost & 1349 & 16980 & $3998.18 \pm 1921.477$ \\
\hline
\end{tabular}

SD: Standard deviation

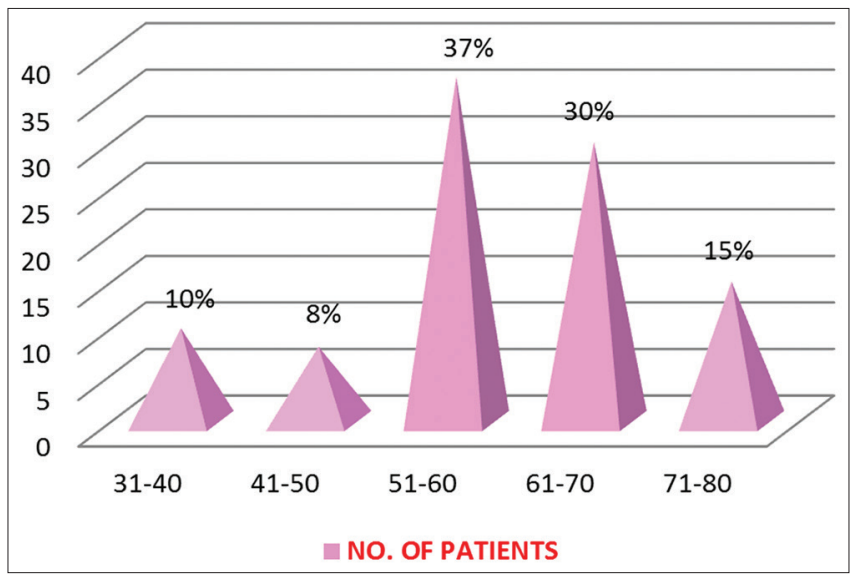

Fig. 1: Distribution according to age group $(n=100)$

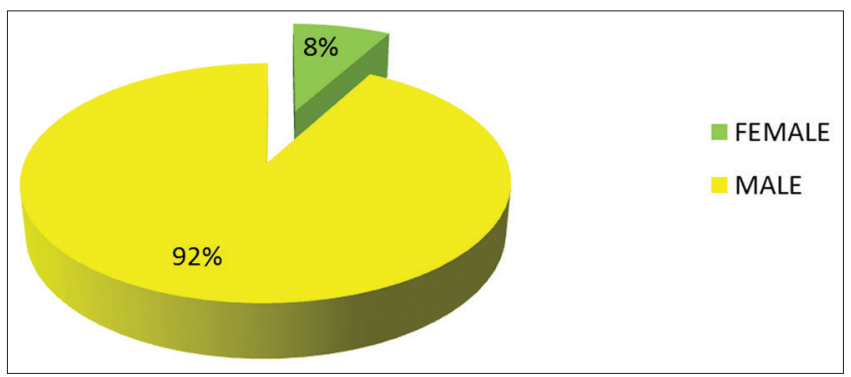

Fig. 2: Distribution according to gender $(n=100)$

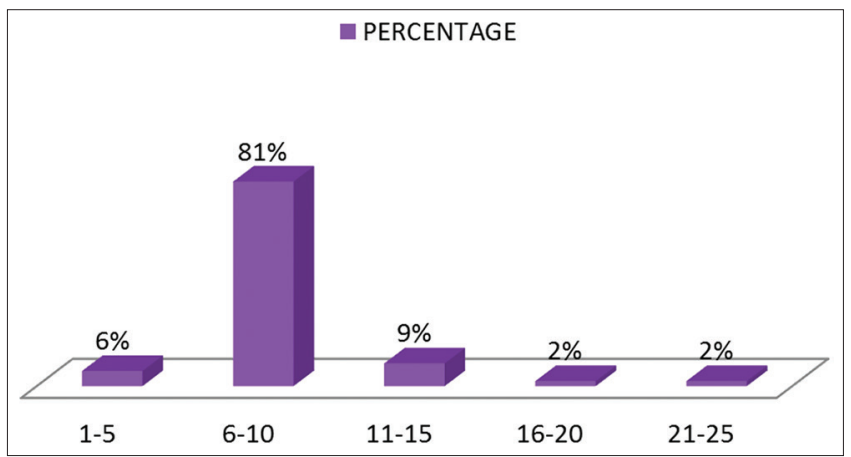

Fig. 3: Distribution of number of days patient stayed in hospital $(n=100)$

baseline information for comparing with other similar studies at the level of the country and the world.

Among 100 patients of the present study population, 92 were male and 8 were female, because of smoking habit was higher in male than female as it is the major risk factor for COPD. It was similar as a study conducted by Kruti et al. [1] and Ramanath et al. [6]

The next component of the study is to find out whether there is an association of different age group of patients and the incidence of hospitalization for COPD. The mean age of study population was $60.33 \pm 10.98$ which is similar as per two studies. In present study, higher number ( $\mathrm{n}=37$ ) of COPD patients is found in the age group of 51-60 years for hospitalization. It was similar as a study done by Kallaru et al. [7], and the results were altered in a study [6] showed higher number of hospitalized COPD patients in 61-70 age group. The reason for the higher incidence in this group is due to severe disease condition by an increase in age. As the COPD is irreversible, it requires continuing medication, and as the increasing age, it requires special medical care such as hospitalization. Hence, the higher age is one of the responsible factors for frequent hospitalization. On the another hand, history of smoking habit is directly proportional to the hospitalization of aged patients.

COPD causes an accelerated depreciation of lung function over time compared with the average of predicted level for a healthy person and is further accentuated by smoking. This study revealed that $90 \%$ and $10 \%$ patients were current smoker and non-smoker, respectively. It was similar as a study done by Kruti et al. [1].

The patients $(\mathrm{n}=81)$ participated in the study were stayed in hospital over a period of $6-10$ days $(81 \%)$. It was similar as a study done by Kruti et al. [1] and Ramanath et al. [6].

This study reveals that patient's cost-of-illness in acute exacerbations of COPD is the sum of total direct medical and total direct non-medical cost.

Direct medical cost is the sum of medicine cost, lab test charges, and hospital charges. Among 100 patients, 91\% of the patients had direct medical cost in between Rs. 1000 and 5000. Total direct medical cost minimum was Rs. 1149 which is higher than the studies done by Kruti et al. [1] and Ramanath et al. [6]. In total direct medical cost, medicine cost was found to be more than the other studies $[1,6]$. The mean \pm SD hospital charge was $7.1 \pm 25.55$ which is lower than the other studies $[1,6]$.

Direct non-medical cost is the sum of travel expenses and food expenses of the patients. In total, $70 \%$ of the patients had direct non-medical cost Rs. $>500,21 \%$ had direct non-medical cost in between Rs. 101 and 500 , and only $9 \%$ had a direct non-medical cost Rs. $<100$. The means of transport used by patients were auto rickshaw, bus, and car. When compared to other studies, travel expenses were less in this study. The mean \pm SD total direct non-medical cost was $700.7 \pm 487.12$ which is higher than the studies reported by Kruti et al. [1] and Ramanath et al. [6].

Total direct cost of the patient is the sum of total direct medical cost and total direct non-medical cost. This study calculated the cost-of-illness of patients, from the day of admission to the day of discharge, with acute 
exacerbations of COPD. The study showed that a minimum cost of Rs. 1349 and a maximum cost of Rs. 16980 were needed for the treatment of acute exacerbations of COPD with a mean cost of Rs. 3998.18 and SD 1921.47.

Only $1 \%$ of the patients had direct cost Rs. $>10000$ and no patients had direct cost Rs. $<1000$. Maximum number of patients $(85 \%)$ had a total direct cost in between Rs. 2001 and 5000, 12\% in between Rs. 5001 and 10000 , and $2 \%$ in between 1001 and 2000 .

The mean cost for the treatment of acute exacerbations of COPD was Rs. 3998.18 which was lower than reported by Veettil et al. [8] and Miravitlles et al. [9]. A study [9] is having total direct cost $36 \%$ higher than the present study. The division of the total direct cost in the present study was $79.56 \%$ medical and $20.44 \%$ non-medical cost which is similar as reported by Kruti et al. [1] and Veettil et al. [8]. According to the inpatient's data available in the present hospital, there were an average 17 patients per month and about 204 patients per year. The mean total direct medical cost was found to be Rs. 3998.18. Extrapolating this to the total of 204 patients admitted with COPD in this institution alone comes to around Rs. 8,15,628 per year

\section{CONCLUSION}

We conclude from the present study that, a minimum cost of Rs.1349 and a maximum cost of Rs. 16980 were needed for the treatment of acute exacerbations of COPD with a mean cost of Rs.3998.18 \pm 1921.47 . Costs of management of acute exacerbation of COPD are exceptionally low in India compared to data obtained from developed countries. Exacerbation prevention resulting in reduced need for inpatient care could lower costs. The development of pharmacoeconomic is at an infancy stage in India at the moment, despite the rapid growth of clinical research. In a country with scarce resources and an evergrowing population with diverse health-care needs, health economics (Pharmacoeconomic evaluation) plays a pivotal role in determining the delivery of equitable and cost-effective health services.

\section{ACKNOWLEDGMENT}

We express our sincere thanks to Shri. S.R. Reddy. M.Pharm Chairman, Navodaya Educational Trust, Dr. S. R. Hegde, Director, NMCH and RC, and Dr. S. Rajashekhar, Medical Superintendent, for giving consent to carry out our project work in this well-equipped and managed hospital. We are also thankful to all the Physicians of $\mathrm{NMCH}$ and RC for their valuable suggestions and help.

\section{CONFLICT OF INTEREST}

No conflict of interest has been reported by the authors of the study, and the study has been concluded with no conflicts.

\section{REFERENCES}

1. Kruti DP, Tarachand L, Kartik S. Economic burden in direct cost of chronic obstructive pulmonary disease at a tertiary care teaching hospital: A prospective observational cohort study. Indian J Pharm Pract 2014:7:61-8.

2. Global Initiative for Chronic Obstructive Lung Disease. Global Strategy for the Diagnosis, Management, and Prevention of Chronic Obstructive Pulmonary Disease: 2017 Report. Available from: http://www.gold.org. [Lat accessed on 20 Feb 2017].

3. World Health Organization. Chronic Obstructive Pulmonary Disease (COPD). Geneva: WHO. Available from: http://www. who.int/respiratory/copd/burden/en/index.html. [Last accessed on 2016 Nov 20].

4. Reema T, Adepu R, Sabin T. Impact of clinical pharmacist intervention on knowledge, attitude and practice (KAP) of patients with Chronic Obstructive Pulmonary Disease. Int J Pharm Pharm Sci 2010;2:54-7.

5. Jindal SK, Gupta D, Aggarwal AN. Guidelines for management of chronic obstructive pulmonary disease (COPD) in India: A guide for physicians. Indian J Chest Dis Allied Sci 2004;46:137-53.

6. Ramanath KV, Sabith JK. Pharmacoeconomic evaluation of acute exacerbations of COPD treatment in a rural tertiary care hospital. Int $\mathrm{J}$ Pharm Sci Res 2012;3:1155-60.

7. Kallaru H, Nagasubramanian V, Balakrishnan H, Gopal K, Palani T. Impact of severity of the disease on cost of illness and quality of life of patients with chronic obstructive pulmonary disease. J Young Pharm 2015;7:106-12.

8. Veettil SK, Salmiah M, Rajiah K, Kumar SB. Cost of acute exacerbation of COPD in patients attending government hospital in Kerala, India. Int J Pharm Pharm Sci 2012;4:659-61.

9. Miravitlles M, Murio C, Guerrero T, Gisbert R. Costs of chronic bronchitis and COPD: A one year follow up study. Chest 2003;123:784- 91 